\title{
MULTIDISCIPLINARY CONSENSUS FOR THE FUTURE DEVELOPMENT OF ADHD SERVICES IN THE UK; WORKING TOGETHER TO IMPROVE PATIENTS CARE
}

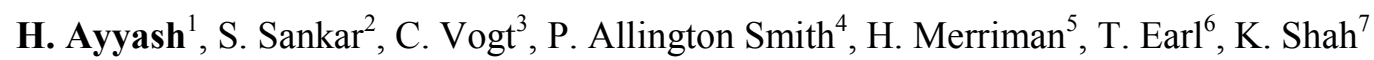 \\ ${ }^{I}$ Department of Paediatrics, Doncaster Royal Infirmary, Doncaster, ${ }^{2}$ CAMHS, Northampton, ${ }^{3}$ CAMHS, \\ Reading, ${ }^{4}$ Brooklands Hospital, Birmingham, ${ }^{5}$ General Practitioner and GP Tutor, Oxfordshire, ${ }^{6}$ Plymouth \\ PCT, Plymouth, ${ }^{7}$ Medicare Health Services, England, UK
}

Aim/objectives: To define a set of standards and validate them as a road map for future development of ADHD services in the UK.

Methods: A multidisciplinary group of clinicians involved in the treatment of patients with ADHD met to define a set of appropriate consensus statements that would define the ideal structure and direction of improving service development in the UK. Forty statements were agreed, covering 10 topics, ranging from commissioning of ADHD services to optimisation of the care pathway. The statements were collated into a questionnaire and passed to other professionals at multidisciplinary meetings around the UK. The questionnaire data was analysed and scores produced for levels of agreement with each statement. Respondents were grouped into child \& adolescent psychiatrists, paediatricians, nurses, trainees and other staff.

Results: 122 respondents scored each statement on a questionnaire and levels of agreement were summated and analysed. Of 40 statements, only 4 scored less than 90\% agreement (Table 1A), with all statements achieving greater than $74.9 \%$ agreement. All other 36 statements achieved greater than $90 \%$ agreement while six out these statements achieved greater than $99.1 \%$ agreement( Table 1B)

Table 1A: The statements that scored less than 9o\% were

\begin{tabular}{|l|l|l|}
\hline 7 & $\begin{array}{l}\text { In each health economy, one expert single commissioner } \\
\text { should be nominated with responsibility for all aspects of } \\
\text { ADHD service provision. Ensuring that the service meets } \\
\text { defined standards and outcomes }\end{array}$ & 81.9 \\
\hline 14 & $\begin{array}{l}\text { Specialist ADHD nurses should take a pivotal role in clinical } \\
\text { case management of co-morbid and complex patient and family } \\
\text { issues }\end{array}$ & 86.0 \\
\hline 17 & $\begin{array}{l}\text { Where possible, specialist ADHD nurses should be able to } \\
\text { prescribe appropriate medical treatment }\end{array}$ & 75.0 \\
\hline 19 & $\begin{array}{l}\text { Where a diagnosis is not possible at assessment, a patient plan } \\
\text { should still be initiated }\end{array}$ & 88.9 \\
\hline
\end{tabular}

Table 1B: Statements with the highest levels of agreement were

\begin{tabular}{|l|l|l|}
\hline 20 & $\begin{array}{l}\text { It is important to integrate care across all appropriate agencies } \\
\text { according to best practice and current guidelines }\end{array}$ & $99.1 \%$ \\
\hline 25 & $\begin{array}{l}\text { Time should be allocated to explaining therapy to the young } \\
\text { person so that they can be involved in treatment decisions }\end{array}$ & $99.1 \%$ \\
\hline 39 & $\begin{array}{l}\text { Integrated multidisciplinary care pathways offer the } \\
\text { opportunity for joint working }\end{array}$ & $98.3 \%$ \\
\hline 33 & $\begin{array}{l}\text { The role of primary care is key to assessment and diagnosis of } \\
\text { ADHD }\end{array}$ & $98.3 \%$ \\
\hline 31 & $\begin{array}{l}\text { Treatment of co-morbid conditions is often necessary } \\
\text { alongside treatment of ADHD }\end{array}$ & $98.3 \%$ \\
\hline 18 & $\begin{array}{l}\text { The patient journey should include the process of assessment, } \\
\text { diagnosis and each subsequent stage of care and management } \\
\text { including transition across services }\end{array}$ & $98.3 \%$ \\
\hline
\end{tabular}

[Table 1 and 2]

Conclusions: All 40 statements therefore have broad support across the ADHD clinical and professional community and reflect strong agreement about what constitutes best practice in the management of ADHD and the direction for future development of services. 